\title{
Attention Deficit and Hyperactivity Disorder According to the Teachers' Perceptions
}

\author{
Ömer Karaman ${ }^{1}$, Hasan Tomakin ${ }^{2}$ \\ ${ }^{1}$ Ordu University Education Faculty The Department of Guidance and Counseling, Ordu/Turkey \\ ${ }^{2}$ The Director of Ordu Guidance and Research Center, Ordu/Turkey
}

Received: 26 June 2016, Accepted: 12 July 2016, Published online: 25 August 2016

(C) Ordu University Institute of Health Sciences, Turkey, 2016

\begin{abstract}
Objective: The Attention Deficit and Hyperactivity Disorder (ADHD), which is one of the student-related problems at primary education schools, is a major health problem that affects all stakeholders in the education process. In the study, the total number of students with ADHD being educated in primary schools of Ordu province has been targeted. So, the prevalence of the students with ADHD will be determined for the first time after an extensive screening in our country. Furthermore, we have aimed to evaluate the success and compliance status of the students with ADHD according to the teachers' perceptions. With the study, the school compliance and success status of the students with ADHD who were diagnosed and in a treatment at a health facility have been examined.

Methods: The universe of the study is composed of 252 students with ADHD consisting of in total 88926 students studying at 330 primary schools in Ordu province in 2011-2012 academic years. In the study, the scanning model was used as the method and "The Attention Deficit and Hyperactive Student Determination Form" developed by the researchers was used as tool. The data obtained in the study was carried out through a request text of the governor which was written by Ordu Counseling and Research Center Management and the schools are informed that the forms which are used for tools should be filled and then sent back.

Results: In the statistical evaluation, the prevalence of ADHD has been found as $0.28 \%$. In addition, 156 (62\%) of 252 students diagnosed with ADHD have been under medical treatment. It has been determined that $4.2 \%$ of these cases related to compliance and success achieved the desired harmony and success but the problems of others continued. On the other hand, it has been determined that only $2.8 \%$ of 96 (38\%) students with ADHD who could not have medical treatment for various reasons achieved compliance and success.

Conclusion: In the study, the number of children diagnosed with ADHD is $0,28 \%$ and it shows us that the students with ADHD cannot be determined largely and the students, teachers and families are in great difficulties. In addition, it is significant that the diagnosed students can not have enough support. On the other hand, the status of untreated students with ADHD despite the medical diagnosis can be attributed to the parents' lack of education, functionality of the treatment and anxiety caused by the side effects of drugs. As a result, some proposals such as to create a strategy for the diagnosis of the students with ADHD all over the country, to configure the school support services besides the medical treatment and to organize parents education program for the families have been presented.
\end{abstract}

Key words: ADHD, Compliance and Performance, Elementary, Students, Ordu

Address for correspondence/reprints:

Ömer Karaman

Telephone number: +9050564874189

E-mail: okaraman44@hotmail.com
DOI: $10.19127 / \mathrm{mbsjohs.52803}$

This research submitted as a oral presentations to İstanbul 2013 World Congress of Psychological Counselling and Guidance 


\section{Introduction}

The Attention Deficit and Hyperactivity Disorder (ADHD), which is one of the studentrelated problems at primary education schools, is a major health problem that affects all stakeholders in the education process.

It is a disorder in which the symptoms such as hyperactivity incompatible with the level of development of ADHD, difficulties in gathering attention and uncontrolled impulse are observed (Guclu and Erkiran, 2005). According to DSM-IV diagnostic criteria determined by the American Psychiatric Association, disorder must last at least 6 months, symptoms should be appeared at least two environments (home, school, workplace, etc.), problems should start before the age of 7 and academic or social functioning should be disturbing (Ozcan et al., 1998). The children with ADHD need to be monitored in classes, camps, group games and at home (Kaidar et al., 2003). On the other hand, conduct disorder, opposite defiant disorder and specific learning difficulties generally accompany to the ADHD (Conner et al., 2003).

The aim of the study is to determine the prevalence of primary school students received the diagnosis of ADHD in health care organizations (Phase I) and to evaluate the compliance and success status according to teachers' perceptions (Phase II).

In the first stage of the study the prevalence of diagnosed ADHD were investigated. In the researches related to the prevalence of $\mathrm{ADHD}$ in the world and our country, the results varying between $1 \%$ and $20 \%$ have been found (Faraone et al., 2003, Polanczyk et al, 2007; Uyan et al., 2014). According to the countries, the causes of the differences in ADHD prevalence can be attributed to the methodological differences (DSM-ICD differences) in the classification of disease, differences in the diagnostic evaluation or the differences in socio-economic structure of the area of the study (Skounti et al., 2007; Polanczyk et al., 2007; Uyan et al., 2014).

Because of the uncertainty of the prevalence of ADHD and the difficulties in its diagnosing, some challenges have been appeared in the development of large-scale projects and creation of strategies. For the ADHD, a clinical practice guideline was published in 2000 for the first time by the American Academy of Pediatrics. A second guide was published for treatment in January 2001. In these guides, a multidisciplinary approach has been suggested by the pediatricians, developmental pediatricians, child and adolescent psychiatrists, psychologists, child neurologists and family doctors for the diagnosis and treatment of ADHD and it has been emphasized that the information which will be given by the family and school must be evaluated besides the DSM-IV diagnostic criteria for the diagnosis (Barley et al., 2004; Uyan et al., 2014).

With the study, total number of diagnosed with ADHD students studying in the primary schools of Ordu province have been aimed. Thus, the prevalence of diagnosed students with ADHD will be determined for the first time after a large-scale screening in our country.

In the second stage of the study, the evaluation of compliance and success status of the students with ADHD according to the teachers' perceptions has been aimed. The ADHD diagnosis is usually made at school ages. Teachers identify these children as late comers to school, forgetful and as in a dream, as individuals who have difficulty in being organized and cannot complete their homework. Therefore, loss of performance, lack of motivation and comprehension problems lead to success under their intelligence (Tahiroglu et al., 2005). Besides the problems about the success, troubles in compliance have been experienced. Lauth and Mackowiack ADHD have identified the students with ADHD as -destructive in the class environment and they have determined that the students with ADHD show both active damaging behavior (talking continuously with desk mates, scouring in the classroom, wandering around humorously etc.) and passive damaging behavior (looking out of the window, being so busy with other things etc.) more than the other students (Act. Ozmen, 2010). Also, in the foreign studies related to the students with ADHD, it has been suggested that there are behavior problems accompanying with ADHD. It has been determined that the behavior disorder is $50 \%$, social withdrawal, fear and depression are 30-35\%, and learning difficulties are $35 \%$. In the studies performed in our country, the rates are $35 \%$ in behavior disorders, $25,9 \%$ in oppositional behavior and $21.7 \%$ in specific learning difficulties (Ozmen, 2010). With the study the school harmony and success of the students with ADHD who were diagnosed and under treatment at a health facility have been investigated. 


\section{Methods}

In the study general screening model was used as the method. General screening models are "scanning arrangements on the whole universe or a group of samples or sample which will be taken from it in order to arrive at an overall judgement about the universe in a universe composed of numerous elements" (Karasar, 1994). In the research "The Attention Deficit and Hyperactivity Diagnosed Student Determination Form" developed by the researchers was used as the data collection tool.

The form was presented to the evaluation of five faculty members after the pre-development. Then arrangements were made and applied to 42 teachers as a preliminary assessment, it was finalized with rearrangements according to the data obtained. In the first phase of the form, diagnostics institutions where the students with ADHD performed and treatment situations were questioned, in the second phase of the form academic success and compliance situations were evaluated in accordance with the opinion of the class advisor. At this stage, the effects of the discontinuing situations of the students with ADHD to their treatment despite being diagnosed with ADHD or drug treatment for the academic achievement and the school adjustment were examined.

The universe of the study is composed of the students with ADHD studying at primary schools in Ordu province in 2011-2012 academic years. The study is limited with the data obtained from the ADHD forms filled by class guide teachers who have students with ADHD in primary schools in the 2011-2012 academic years.

The data obtained in the study was carried out through a request text of the governor which was written by Ordu Counseling and Research Center Management and the schools are informed that the forms which are used for tools should be filled and then sent back. In the controls in the process of collecting the forms, incomplete and irregular shipments were identified and requested again and it was tried to obtain the entire universe.

\section{Results}

The findings obtained in the study are composed of 252 ADHD diagnosed students consisting of a total of 88926 students who study in 330 primary schools of Ordu province in 2011-2012 academic years.
Table 1. The Distribution of ADHD Diagnosed

Students According to the Class and Gender

\begin{tabular}{ccccccc}
\hline $\mathbf{C}$ & $\mathbf{F}$ & $\mathbf{M}$ & $\mathbf{T}$ & $\mathbf{C} / \mathbf{S}$ & $\mathbf{U}$ & $\mathbf{C / S}$ \\
\hline 1 & 6 & 30 & 23 & 1 & 10 & 1 \\
2 & 7 & 26 & 20 & 2 & 12 & - \\
3 & 2 & 32 & 20 & - & 8 & - \\
4 & 5 & 26 & 18 & 1 & 13 & 2 \\
5 & 4 & 28 & 22 & - & 15 & - \\
6 & 6 & 24 & 19 & - & 12 & - \\
7 & 3 & 22 & 18 & 2 & 16 & - \\
8 & 2 & 29 & 16 & 1 & 10 & - \\
\hline
\end{tabular}

$\mathrm{C}=$ Classes, $\mathrm{F}=$ Female, $\mathrm{M}=$ Male, $\mathrm{T}=$ Treated, $\mathrm{C} / \mathrm{S}=$ Compliance/Success, $\mathrm{U}=$ Untreated

In the statistical evaluation the prevalence of ADHD has been found as $0.28 \%$. In the DSM booklet (APA, 1994) the frequency has been projected as $3-5 \%$. In the studies conducted in our country, $2-12 \%$ of the school-age children are thought to be affected although there is no definite opinion unity (Kayaalp, 2008).

In addition, $156(62 \%)$ of 252 ADHD diagnosed students have been under medical treatment. It has been determined that $4.2 \%$ of them achieved both desired harmony and academic success but the problems of the others have been continued. On the other hand, it has been determined that only $2.8 \%$ of $96(38 \%)$ students with ADHD who cannot have medical treatment for various reasons achieved compliance and academic success.

\section{Discussion}

According to the data obtained in the research, the number of ADHD diagnosed students is very low. Because the universes of earlier studies are consisted of children admitted to the clinic, ADHD screening conducted in some schools or a few students who were diagnosed with ADHD. But, as the ADHD diagnosed students studying in primary schools of all the villages, towns and districts of the province were identified in the study, the rates may have been lower. This situation can be connected to the diagnostic difficulties because of the socioeconomic reasons in villages and towns and the width of the universe. On the other hand, a multidisciplinary work must be for diagnosis of the ADHD. Because, there are difficulties in diagnosing and and therefore observations of parents and teachers play an important role (Ercan and Aydin, 1999). The observation results of the students for both academic success and peer communication and experienced behavior problems 
in the school environment are distinguishing (Atkins and Pelham, 2001). Researchers has emphasized that the opinions of teachers play a major role in treatment as well as in diagnostics (Ghanizadeh et al., 2006, Karabekiroglu et al., 2009). But in the study of teachers' knowledge about ADHD, it has been determined that the teachers have insufficient information. Similarly, it has been determined that the families who have children with ADHD do not have adequate knowledge or the information they learn may be incomplete and inaccurate (Aslan, 2013; Gol and Babik, 2013).

Despite the students with ADHD have treatment, their harmony and success situations are not at the desired level, and this can be explained with the lack of knowledge and skills of the families on these subjects and insufficiency of the school support services and the medical treatment. The ADHD treatment should be in scope containing behavioral, cognitive, social and familial areas. As well as drug treatment psychotherapy and psychosocial interventions are essential (Kayaalp, 2008). But the psychotherapy and psychosocial supports have not reached a sufficient level in our country. Meeting of the requirements by the psychotherapy services are not possible according to the conditions of our country. Because, only five of every hundred people can access to mental health professionals in our country (Cam and Engin, 2015).

In the domestic and international studies, it has been reported that the prevalence of ADHD range between $2 \%$ and $12 \%$. In the study, the number of children diagnosed with ADHD is $0,28 \%$ and it shows us that the students with ADHD cannot be determined largely and the students, teachers and families are in great difficulties. In addition, it is significant that the diagnosed students can not have enough support. On the other hand, the status of untreated students with ADHD despite the medical diagnosis can be attributed to the parents' lack of education, functionality of the treatment and anxiety caused by the side effects of drugs.

\section{Conclusion}

As a result, some proposals such as to create a strategy for the diagnosis of the students with ADHD all over the country, to configure the school support services besides the medical treatment and to organize parents education program for the families have been presented.

Informed Consent: Necessary information using the patient information form and consent form was taken from the participants.

Peer-review: Externally peer-reviewed.

Author Contributions: Concept-ÖK, HT, DesignÖK, HT, Supervision- ÖK, HT, Funding-ÖK, HT, Materials-ÖK, HT, Data Collection and/or Processing-ÖK, HT, Analysis and/or InterpretationÖK, HT, Literature Review- ÖK, Writing-ÖK, HT, Critical Review-ÖK

Conflict of Interest: No conflict of interest was declared by the authors.

Financial Disclosure: The authors declared that this study hasn't received any financial support.

\section{References}

Aslan F. Determining the awareness level of parents from different socio-economic levels regarding the Attention Deficit and Hyperactivity Disorder (ADHD) bearing children, Master of Science Thesis, Hacettepe University, Graduate School of Health Sciences, Public Health Nursing Program, Ankara, 2013.

Atkins M, \& Pelham W E. School based assesment of attention deficit hyperactivity isorder. Journal of Learning Disabilities 2001; 24: 197- 203.

Barkley R A. Adolescents with attention deficit hyperactivity disorder: An overview of empirically based treatments. Journal of Psychiatric Practice 2004; 10(1): 39-56.

Cam O, Engin E. Psychotherapy and Nursing. Turkiye Klinikleri J Psychiatr Nurs-Special Topics 2015; 1(1): 87-94

Conner DF, Edwards G, Fletcher KE, Baird J, Barkley RA, Steingard RJ. Correlates of comorbid psychopatology in children with ADHD. J Am Acad Child Adoles Psychiatry 2003; 42(2): 193200.

DSM-IV, Diagnostik and statiscal manual of mental disorders. APA, 1994.

https://justines2010blog.files.wordpress.com/2011/03 /dsm-iv.pdf 
Ercan ES, Aydin C. Attention Deficit Hyperactivity Disorder. A Ekfli (ed.) I'm not patient Child Health and psychosocial aspects of the disease. 1. Ed. Istanbul: Nobel Tip Kitap Evleri; 1999. p. 270-284.

Faraone SV, Sergeant J, Gillberg C, Biederman J. The worldwide prevalence of ADHD: is it an American condition? World Psychiatry 2003; 2(2): 104-13.

Ghanizadeh A, Bahredar MJ, \& Moeini SR. Knowledge and attitudes towards attention deficit hyperactivity disorder among elementary school teachers. Patient Education Counseling 2006; 63: 84-88.

Gol I, Babik A. The Competency of Primary School Classroom Teachers in the Recognition of the Children with Attention Deficit/Hyperactivity Disorder. Deuhyo Ed 2013; 6 (4): 207-213.

Guclu O, Erkiran M. Personality disorders in parents of children with attention deficit hyperactivity disorder Klinik Psikiyatri 2005; 8: 18-23.

Kaidar I, Weiner J, Tannock R. The attribution of children with attention-deficit/hyperactivity disorder for their problem behaviors. Attention Dis 2003; 6 (3): 99-109.

Karabekiroglu K, Cakın M N, Ozcan OO, Toros F, Oztop D, Ozbakan B, et al. Stigmatization and Misinterpretations on ADHD and Auti sm: A Multi-Central Study with Elementary School Teachers and Parents. Klinik Psikiyatri Dergisi, 2009; 12: 79-89.

Karasar, N. Methods Of Scientific Research.5. ed, Ankara: Research and Educational Consultancy Ltd.; 1994

Kayaalp L. Attention Deficit Hyperactivity Disorder. İ.Ü. Cerrahpaşa Faculty of Medicine Continuing Medical Education Activities (Common Psychiatric Disorders In Turkey Symposium Series) 2008; 62:147-152

Ozcan E, Egri M, Kutlu O, Yakinci C, Karabiber H, Genc M. ADHD prevalence among school-age childeren: a preliminary study. Turgut Özel Tip Merkezi Dergisi 1998; 5(2,3): 138-142.

Ozmen SK. Attention Deficit Hyperactivity Disorder (ADHD) at School. Mersin Üniversitesi Eğitim Fakültesi Dergisi, 2010; 6(2): 1-10.

Polanczyk G, Lima MS, Horta BL, et al. The worlwide prevalence of ADHD: A systematic review and metaregression analysis. Am J Psychiatry 2007; 164(6): 942-8.
Polanczyk G, Rohde LA. Epidemiology of attention deficit/hyperactivity disorder across the lifespan. Current Opinion in Psychiatry 2007; 20(4): 38692.

Skounti M, Philalithis A, Galanakis E. Variations in prevalence of attention- deficit/hyperactivity disorder worlwide. Eur J Pediatr 2007; 166(2): 117-23.

Tahiroglu AY, Avc1 A, Firat S, Seydaoğlu G. Attention Deficit Hyperactivity Disorder: Subtypes. Anadolu Psikiyatri Dergisi 2005; 6: 510.

Uyan Z, Ceyhun Peker AG, Tekiner AS, Ulukol B. Investigation of Prevalence of Attention Deficit Hyperactivity Disorder among Adolescents. Konuralp T1p Dergisi 2014;6(3):21-26 